Research Article

\title{
Continentality and Oceanity in the Mid and High Latitudes of the Northern Hemisphere and Their Links to Atmospheric Circulation
}

\author{
Edvinas Stonevicius $(\mathbb{D}$, Gintautas Stankunavicius, and Egidijus Rimkus \\ Institute of Geosciences, Vilnius University, Vilnius, Lithuania \\ Correspondence should be addressed to Egidijus Rimkus; egidijus.rimkus@gf.vu.lt
}

Received 27 March 2018; Revised 20 July 2018; Accepted 5 September 2018; Published 30 September 2018

Academic Editor: Roberto Fraile

Copyright ( $\odot 2018$ Edvinas Stonevicius et al. This is an open access article distributed under the Creative Commons Attribution License, which permits unrestricted use, distribution, and reproduction in any medium, provided the original work is properly cited.

\begin{abstract}
The climate continentality or oceanity is one of the main characteristics of the local climatic conditions, which varies with global and regional climate change. This paper analyzes indexes of continentality and oceanity, as well as their variations in the middle and high latitudes of the Northern Hemisphere in the period 1950-2015. Climatology and changes in continentality and oceanity are examined using Conrad's Continentality Index (CCI) and Kerner's Oceanity Index (KOI). The impact of Northern Hemisphere teleconnection patterns on continentality/oceanity conditions was also evaluated. According to CCI, continentality is more significant in Northeast Siberia and lower along the Pacific coast of North America as well as in coastal areas in the northern part of the Atlantic Ocean. However, according to KOI, areas of high continentality do not precisely correspond with those of low oceanity, appearing to the south and west of those identified by CCI. The spatial patterns of changes in continentality thus seem to be different. According to CCI, a statistically significant increase in continentality has only been found in Northeast Siberia. In contrast, in the western part of North America and the majority of Asia, continentality has weakened. According to KOI, the climate has become increasingly continental in Northern Europe and the majority of North America and East Asia. Oceanity has increased in the Canadian Arctic Archipelago and in some parts of the Mediterranean region. Changes in continentality were primarily related to the increased temperature of the coldest month as a consequence of changes in atmospheric circulation: the positive phase of North Atlantic Oscillation (NAO) and East Atlantic (EA) patterns has dominated in winter in recent decades. Trends in oceanity may be connected with the diminishing extent of seasonal sea ice and an associated increase in sea surface temperature.
\end{abstract}

\section{Introduction}

Continentality and oceanity are important parameters which describe local climatic conditions. They demonstrate the extent to which local climate is influenced by sea-landmass interactions. Like most other climate indicators, these parameters are dynamic and are related to both global climate change and consequently changes in atmospheric circulation.

Continentality is primarily affected by a range of climatic variables, such as latitude, distance to sea, and atmospheric circulation. In most cases, continentality index calculations are based on the annual air temperature range and latitude. A larger annual air temperature range is associated with higher thermal contrasts and greater continentality.
Under changing climate conditions, continentality could be affected in different ways [1]. Due to global climate change, air temperature tends to increase in most parts of the world. In recent decades, the fastest warming was observed in the mid latitudes of the Northern Hemisphere [2]. Therefore, analysis of changes in different climate indices, including of continentality changes in the mid and high latitudes of the Northern Hemisphere, is of considerable importance. In areas where winter air temperatures have a more substantial positive trend than their summer counterparts, corresponding values of the continentality index decline, and vice versa. An increase in the annual cycle's amplitude in the mid latitudes of the Northern Hemisphere has been identified over the past two decades: 
i.e., winter air temperatures increased slightly, while changes in the summer were more significant [2-4].

However, changes in the annual air temperature range vary considerably in different regions, and therefore, trends in climate continentality also differ. Regional investigations of climate continentality began in the first half of the twentieth century. Gorczynski [5], Brunt [6], Raunio [7], and others described the climate continentality of different localities on the basis of the annual air temperature range. Hirschi et al. [1] analysed the global continentality change using NCEP/NCAR reanalysis data in the period 1948-2005. A significant decline in continentality was noted in the Arctic and Antarctic due to a large increase in the temperature of the coldest month. However, the continentality index in Southeastern Europe also increased [1].

In recent years, regional features of continentality and oceanity have been analysed in Greece [8], Turkey [9], and Pakistan [10]. It has been determined that climate continentality has intensified in the Iberian Peninsula [11]. Negligible increases in continentality were also observed in Slovakia [12] and no significant changes were found in the Czech Republic [13], while a statistically significant increase in continentality was identified in the Middle East and North Africa [14]. Moreover the authors of [14] argue that regional circulation patterns (e.g., over the Mediterranean) do not play a critical role in determining the trends identified in continentality. Rather, they refer to changes in large-scale atmospheric circulation over the North Atlantic [14].

Moving poleward in the Northern Hemisphere, landmasses become larger, so continentality tends to be less pronounced in periods with enhanced zonal circulation. In contrast, it becomes more noteworthy with enhanced meridional circulation [15] and the greater influence of the continental Arctic air masses [16].

Changes in continentality affect both natural (such as vegetation zones) and anthropogenic (e.g., water resources and agriculture) systems, so investigations of changes in continentality are of great importance [8, 14, 17]. Furthermore, relatively few studies have analysed continentality and its changes on a global scale [1]. In addition, a lack of research exists analysing the effect of atmospheric circulation on continentality index values.

Therefore, the aim of this research is to evaluate the spatial distribution of the widely accepted Conrad's Continentality Index (CCI) and Kerner's Oceanity Index (KOI) in the middle and high latitudes of land areas of the Northern Hemisphere, as well as to evaluate the changes in these indexes since the middle of the twentieth century and their connections to atmospheric circulation.

\section{Methods}

The annual air temperature range and latitude were included in the continentality index formulas developed by Gorczynski [18], Johansson [19], Conrad [20], Raunio [7], Marsz and Rakusa-Suszczewskis [21], and others.

In this research, continentality was evaluated using the CCI proposed by Conrad [20]:

$$
\mathrm{CCI}=\frac{1.7\left(T_{\max }-T_{\min }\right)}{\sin (\varphi+10)}-14,
$$

where $T_{\max }\left({ }^{\circ} \mathrm{C}\right)$ is the mean temperature of the warmest months of the year, $T_{\min }\left({ }^{\circ} \mathrm{C}\right)$ is the mean temperature of the coldest months of the year, and $\varphi$ is the latitude.

A large annual range of air temperatures results in larger index values and consequently indicates a more continental climate. The smallest differences can be observed in the most oceanic climate conditions. The territories where index values range from -20 to 20 can be described as hyperoceanic, from 20 to 50 as oceanic, from 50 to 60 as subcontinental, from 60 to 80 as continental, and from 80 to 120 as hypercontinental [11].

In 1905, Kerner proposed an oceanity index [22]. This index represents the ratio of the mean monthly air temperature difference between October and April and the difference between mean monthly temperatures of the warmest and coldest months. Small or negative values indicate high continentality, whereas high index values indicate marine climate conditions [10]. The oceanity index (KOI) according to Kerner was evaluated as follows:

$$
\mathrm{KOI}=\frac{100\left(T_{\mathrm{oct}}-T_{\mathrm{apr}}\right)}{T_{\max }-T_{\min }},
$$

where $T_{\text {oct }}$ and $T_{\text {apr }}\left({ }^{\circ} \mathrm{C}\right)$ are the mean monthly temperature in October and April, respectively, and $T_{\max }$ and $T_{\text {min }}$ $\left({ }^{\circ} \mathrm{C}\right)$ are the same as in Equation (1). This index is based on the assumption that due to higher thermal water inertia in marine climates, springs are colder than autumns, whereas in continental climates, springs tend to demonstrate higher or similar temperatures as in autumn. The oceanity of the climate increases with index values. Small or negative values demonstrate continental climate conditions, while large values indicate a marine climate [8]. In order to visualise the spatial distribution of $\mathrm{KOI}$, the following classes of index were used in this research: less or equal to $-10=$ hypercontinental; from -9 to $0=$ continental; from 1 to $10=$ subcontinental; from 11 to $20=$ oceanic; and from 21 to $50=$ hyperoceanic.

The CCI and especially KOI are only feasible in regions with distinct seasonal air temperature changes. We opted to analyse continentality and oceanity above a latitude of $30^{\circ}$ in the Northern Hemisphere, where temperature seasonality is high.

The mean monthly air temperature values for the period 1950-2015 above the land were derived from the CRU TS4.00 database [23]. The grid cell size was $0.5 \times 0.5^{\circ}$. CRU TS is a high-resolution global data set, covering all landmasses between $60^{\circ} \mathrm{S}$ and $80^{\circ} \mathrm{N}$. The priority of the CRU TS data set is its completeness, having no missing data over the land. Particular attention is paid to data quality control [24]. However, the data set is not strictly homogeneous, and larger uncertainties can be found over regions with a sparse network of meteorological stations, especially deserts and mountains $[25,26]$. Nevertheless, in spite of some limitations, the CRU TS database is widely used for climate investigations [27-29]. 
The long-term trends of the continentality/oceanity index during the period 1950-2015 were calculated using Sen's slope test. The statistical significance of the trend values was evaluated using the Mann-Kendall test. Changes with $p$ values of less than 0.05 were considered statistically significant. 1981-2010 continentality/oceanity index normals were also determined.

We also analysed the impact of atmospheric circulation on seasonal temperature indicators and thus on the variability of climate continentality and oceanity. The Northern Hemisphere teleconnection patterns (NHTPs) derived from $500 \mathrm{hPa}$ height field are the leading modes of low-frequency atmospheric circulation variability in the Northern Hemisphere. The data are available from the website of NOAA Center for Weather and Climate Prediction. We selected eight of the 10 available NHTPs because they alone can explain two-thirds of low-frequency atmospheric circulation variability within $\mathrm{NH}$ extratropics, and they are active all year and have the same retrieval procedure (Table 1).

One group of NHTPs (NAO and EA) is prominent over the North Atlantic and Europe. Others-SCA, POL, and EA/WR - span over the mid and high latitudes of Eurasia, and PNA, EP/NP, and WP represent the North Pacific and North America.

The correlations between $T_{\min }$ and the mean JanuaryMarch NHTP values, $T_{\max }$ and July-September NHTP values, $T_{\text {apr }}$ and March-May NHTP values and $T_{\text {oct }}$ and September-November NHTP values were analysed to determine the effect of atmospheric circulation on the variation of surface air temperatures as well as on CCI and KOI. The three-month average of NHTP indexes in correlations was used in order to avoid mismatching $T_{\min }$ and $T_{\max }$ with the particular coldest winter/warmest summer month. The same procedure was subsequently applied to $T_{\text {apr }}$ and $T_{\text {oct }}$ in order to unify the assessment of the impact of atmospheric circulation on both CCI and KOI.

NHTP indexes are available at a monthly time scale. However, every index value represents the three-month period centred on a particular month owing to its calculation procedure.

\section{Results and Discussion}

3.1. Climate Norm and Determinant. In the climatological standard normal period (1981-2010), the hypercontinental climate (CCI values $>80$ ) was in Northeast Siberia, while the hyperoceanic climate (CCI values $<20$ ) was identified along the Pacific coast of North America and in coastal areas in northern parts of the Atlantic Ocean (Figure 1). The surface air temperature of the coldest month represented the most important determinant of CCI values in almost the whole study area (Figure 2). This can be explained by the fact that, in a substantial part of the analysed territory, winter temperature fluctuations were greater than their summer counterparts. Meanwhile, the temperature of the warmest month was the principal factor for CCI only in the western part of the Mediterranean basin.

The high continentality (CCI) within central-northern North America and Northeastern Eurasia (East Siberia) was
TABLE 1: Standardised Northern Hemisphere teleconnection indexes used in the study.

\begin{tabular}{lc}
\hline Abbreviation & Full name \\
\hline NAO & North Atlantic Oscillation \\
EA & East Atlantic pattern \\
WP & West Pacific pattern \\
EP/NP & East Pacific/North Pacific pattern \\
PNA & Pacific/North American pattern \\
EA/WR & East Atlantic/West Russian pattern \\
SCA & Scandinavian pattern \\
POL & Polar/Eurasian pattern \\
\hline
\end{tabular}

primarily influenced by very low air temperatures in the coldest month of the year. The Siberian High (SH) and North American High (NAH) favour extreme negative surface temperatures during the winter in the larger part of Northern Asia and the northernmost parts of North America. These are seasonal high-pressure systems composed of cold and dry air; however, $\mathrm{SH}$ is much more persistent than $\mathrm{NAH}$, and due to local topography (mountain valleys), it initiates the largest temperature inversions over the northeastern part of Siberia [30, 31]. Relatively high coldest month temperatures in the larger part of Europe, Southeastern USA, and the Pacific coast of North America seem to be responsible for the low CCI values there.

The strongest oceanity (large KOI) was observed within coastal areas of the Arctic Ocean, North Atlantic, Mediterranean, and the Far East (Figure 1). The lowest KOI was found within the inner part of Eurasia (particularly Central Asia and the Tibetan Plateau), the Canadian Prairies, and Yukon. Such spatial variation of KOI can partly be explained by sea surface temperature (SST) differences in October and April: October SST was always higher than April SST in the Arctic, North Atlantic, Mediterranean, and so forth; moreover, many coastal areas in high latitudes in April are covered by sea ice, but in October they are ice-free.

The relationship between KOI and the average temperature of the warmest $\left(T_{\max }\right)$ and coldest $\left(T_{\min }\right)$ months is weak $\left(R^{2}<0.15\right)$. Both the April and October temperatures have a greater effect on variations in the KOI (Figure 3). Fluctuations of air temperature in April play a leading role (especially in the central parts of continents), whereas October temperatures are more important in coastal areas. The land surface temperature in April is usually higher than in October at the same latitude over inland areas as long as there is no snow cover.

The areas of low KOI do not exactly correspond with those of high CCI; indeed, low KOI areas are situated to the south and west of their high CCI counterparts (Figure 1). Cyclonic activity as well as mean wind speed over the Arctic, North Atlantic, and North Pacific is higher in October than in April and represents one of the main drivers of heat flux to the high latitudes, thus contributing to the high $\mathrm{KOI}$ in the coastal areas of these regions $[32,33]$.

3.2. Long-Term Trends. Annual minimum and maximum monthly air temperatures and temperatures in April and October increased across the majority of the study area in the 


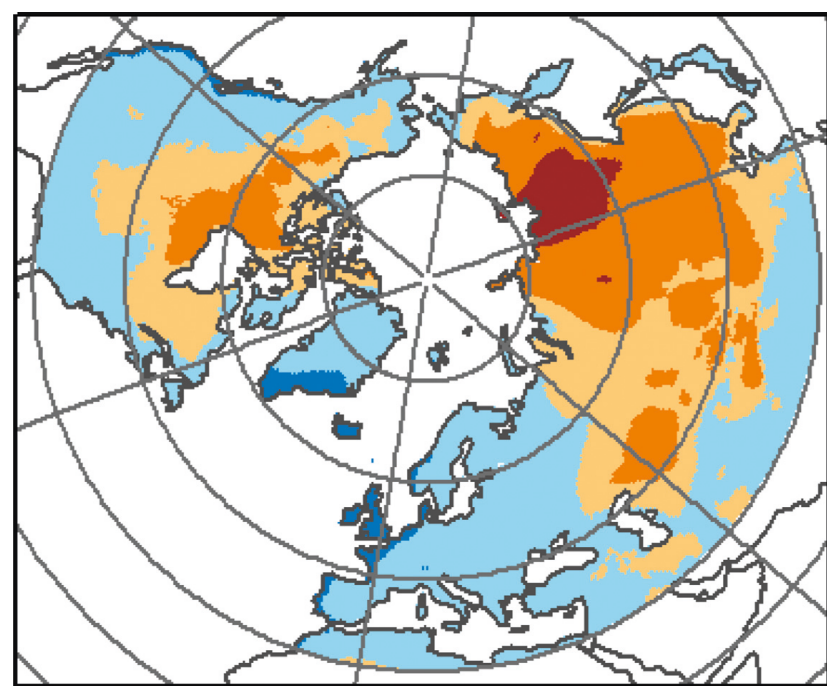

Hyperoceanic

Oceanic/maritime

Subcontinental

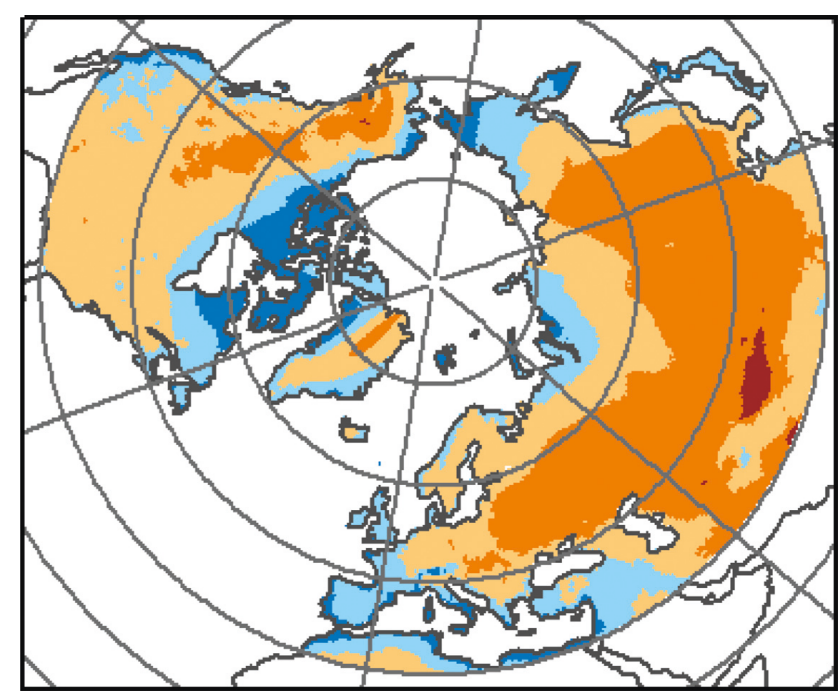

Hyperoceanic

Oceanic/maritime

Subcontinental (a)

Continental

Extreme/hypercontinental
Continental

Extreme/hypercontinental

(b)

Figure 1: The climatological standard normal (1981-2010) of (a) Conrad's Continentality Index (CCI) and (b) Kerner's Oceanity Index (KOI).

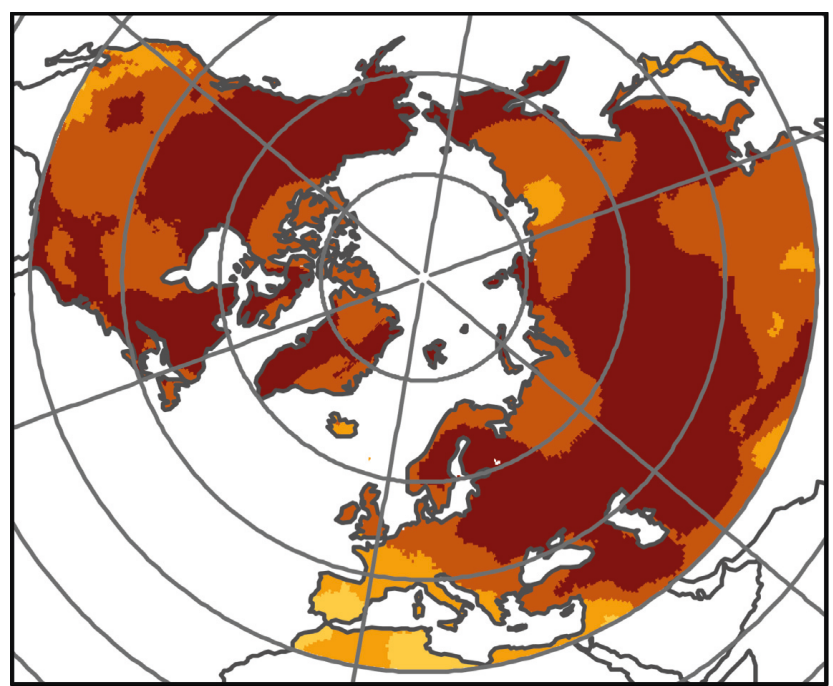

$0.00-0.20$

$0.21-0.40$

$0.41-0.60$

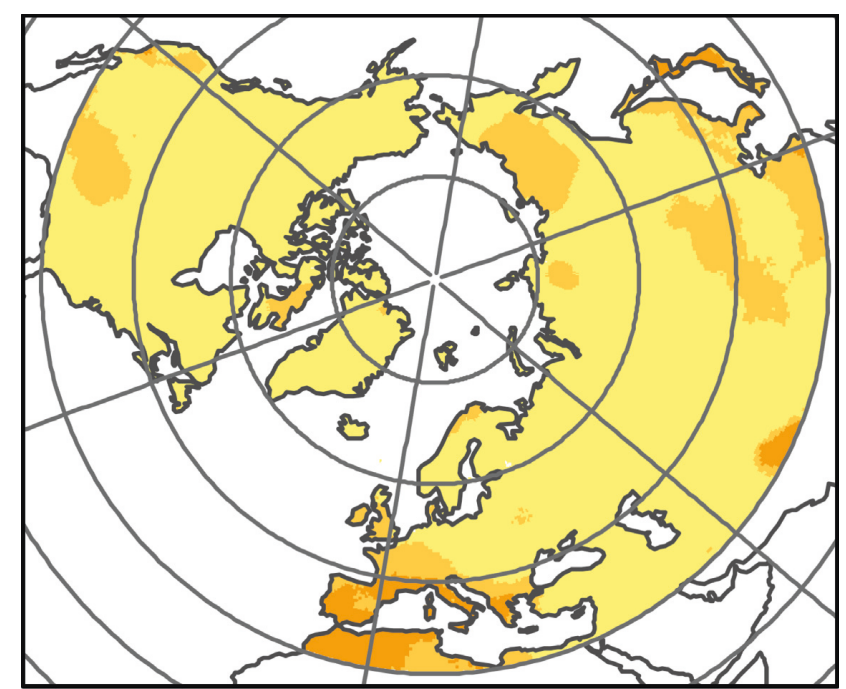

$0.00-0.20$

0.21-0.40

$0.41-0.60$
$0.61-0.80$

$0.81-1.00$

(b)

(a)

Figure 2: The determination coefficient $\left(R^{2}\right)$ between Conrad's Continentality Index (CCI) and the average temperature of the (a) coldest $\left(T_{\min }\right)$ and (b) warmest $\left(T_{\max }\right)$ months in 1950-2015.

period 1950-2015 (Figure 4). The annual minimum monthly temperature increased by more than $0.5^{\circ} \mathrm{C} / 10$ years in Western Russia, East Siberia, and in some parts of Central Asia (Figure 4), while the largest rise of $T_{\min }$ was found in the northwestern part of North America (more than $1.0^{\circ} \mathrm{C} / 10$ years). The annual minimum monthly temperature declined slightly only in the northeastern part of Siberia and in the eastern part of North America.

The magnitude of the annual maximum monthly temperature $\left(T_{\max }\right)$ trend was smaller than that of $T_{\min }$ in 1950-2015. Trends above $0.25^{\circ} \mathrm{C} / 10$ years were observed in the northeastern part of Siberia, in large parts of Central Asia 


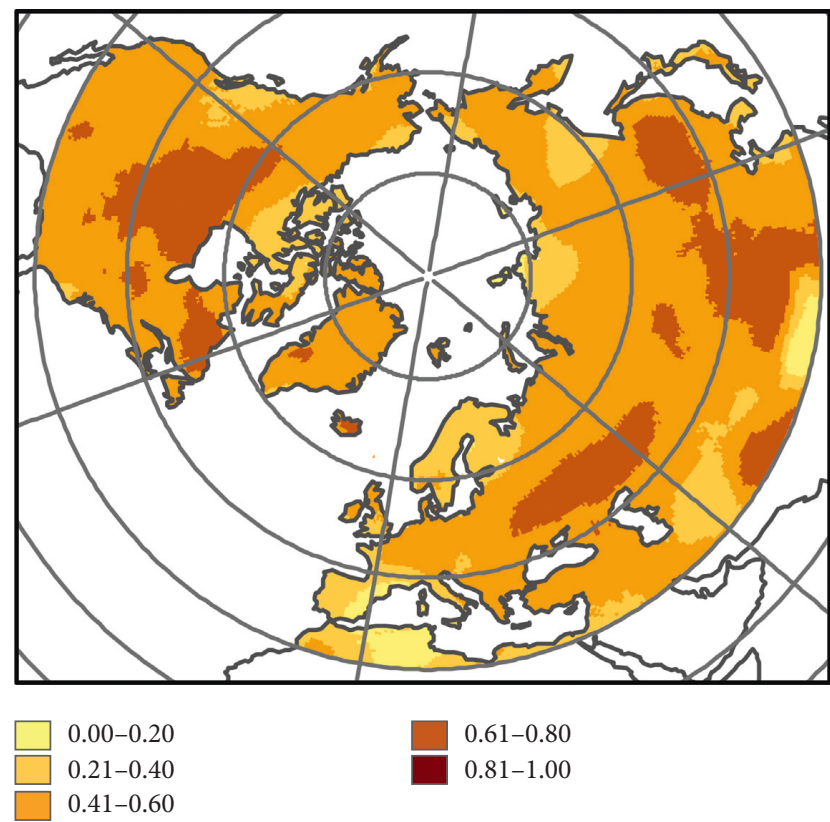

(a)

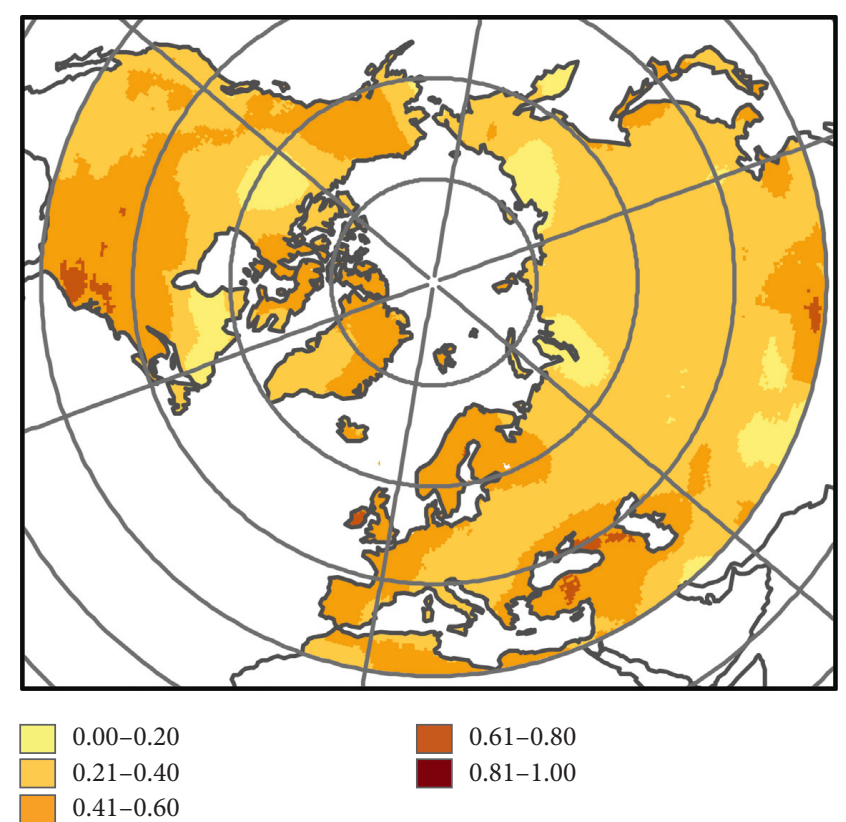

(b)

FIGURE 3: The determination coefficient $\left(R^{2}\right)$ between Kerner's Oceanity Index (KOI) and the average temperature in (a) April ( $\left.T_{\text {apr }}\right)$ and (b) October $\left(T_{\text {oct }}\right)$ in 1950-2015.

and Europe, and northern North America. A larger $T_{\text {min }}$ increase rate relative to $T_{\max }$ reduced the annual temperature amplitude and CCI over the majority of North America, Asia, and Eastern Europe (Figure 5). In Southwestern Europe, the CCI increased in the areas where $T_{\max }$ grew more than $T_{\min }$. In the northeastern part of Siberia and the eastern part of the USA, the increase of CCI was related to a decrease of $T_{\min }$ and a rise of $T_{\max }$.

Some teleconnection patterns also demonstrated clear tendencies: the prevalence of a certain phase in the last few decades-EA (positive), EA/WR (negative), and EP/NP (negative) due to the same reasons as for NAO.

A strong reduction in oceanity in most of Europe and Mongolia in addition to an increase in the Caspian SeaCaucasus region as well as in a large part of North America during recent decades also indicates the prevalence of certain phases of particular circulation patterns in April and October: EA, EA/WR, SCA, POL, and PNA. However, recent research has argued that heating anomalies over the subtropical Northwestern Atlantic, as well as storm-track activity over the North Atlantic, are able to produce wellorganised EA/WR-like wave patterns with associated widespread anomalies from the continental USA to Central Asia, with the strongest impact on the Caspian Sea and Western European regions [34].

In 1950-2015, through April ( $\left.T_{\text {apr }}\right)$ and October $\left(T_{\text {oct }}\right)$, the increase in monthly temperatures was greatest in areas near the Arctic Ocean $\left(>0.50^{\circ} \mathrm{C} / 10\right.$ years) (Figure 4$)$. In lower latitudes, both April and October temperatures increased, but the spatial pattern of trends was very different, especially in Asia and North America. The April temperature trend was highest in East Siberia and the eastern part of Central Asia, while October temperatures increased more significantly in the northern and northeastern parts of Siberia and in some areas of Central Asia. Insignificant negative changes were observed across a large part of North America in October. The differences in the trends of spatial patterns resulted in statistically significant changes in the KOI over the Baltic Sea region and parts of Siberia and Mongolia (Figure 5). The climate became more oceanic in the northern part of Canada, outermost parts of the Far East and Africa, and large parts of the Mediterranean region.

3.3. Atmospheric Circulation. Atmospheric circulation is an important driver of spatial distribution and temporal variation of selected temperature parameters: $T_{\min }, T_{\max }$, $T_{\text {apr }}$, and $T_{\text {oct }}$. The correlation between Northern Hemisphere teleconnection patterns and the analysed temperature parameters permits identification of the areas where atmospheric circulation has a significant effect on the temporal variation of seasonal temperature differences and thus CCI and KOI (Figure 6). The used teleconnection patterns are identified using rotated principal component analysis, and in theory, there should not be multicollinearity between different patterns and their effects on temperature indicators.

Atmospheric circulation had the largest effect on $T_{\min }$ variation in latitudes between $40^{\circ}$ and $60^{\circ}$ (Figure 6). NAO had a statistically significant positive correlation with $T_{\min }$ in the larger part of Eurasian mid and high latitudes. Therefore, CCI tends to decrease in Northern Eurasia during winters with a prevailing positive NAO phase and vice versa during a negative NAO phase (Figure 6). NAO, or its hemispheric counterpart Arctic oscillation (AO), has a significant impact on the shape and strength of the Siberian High (SH) and thus 

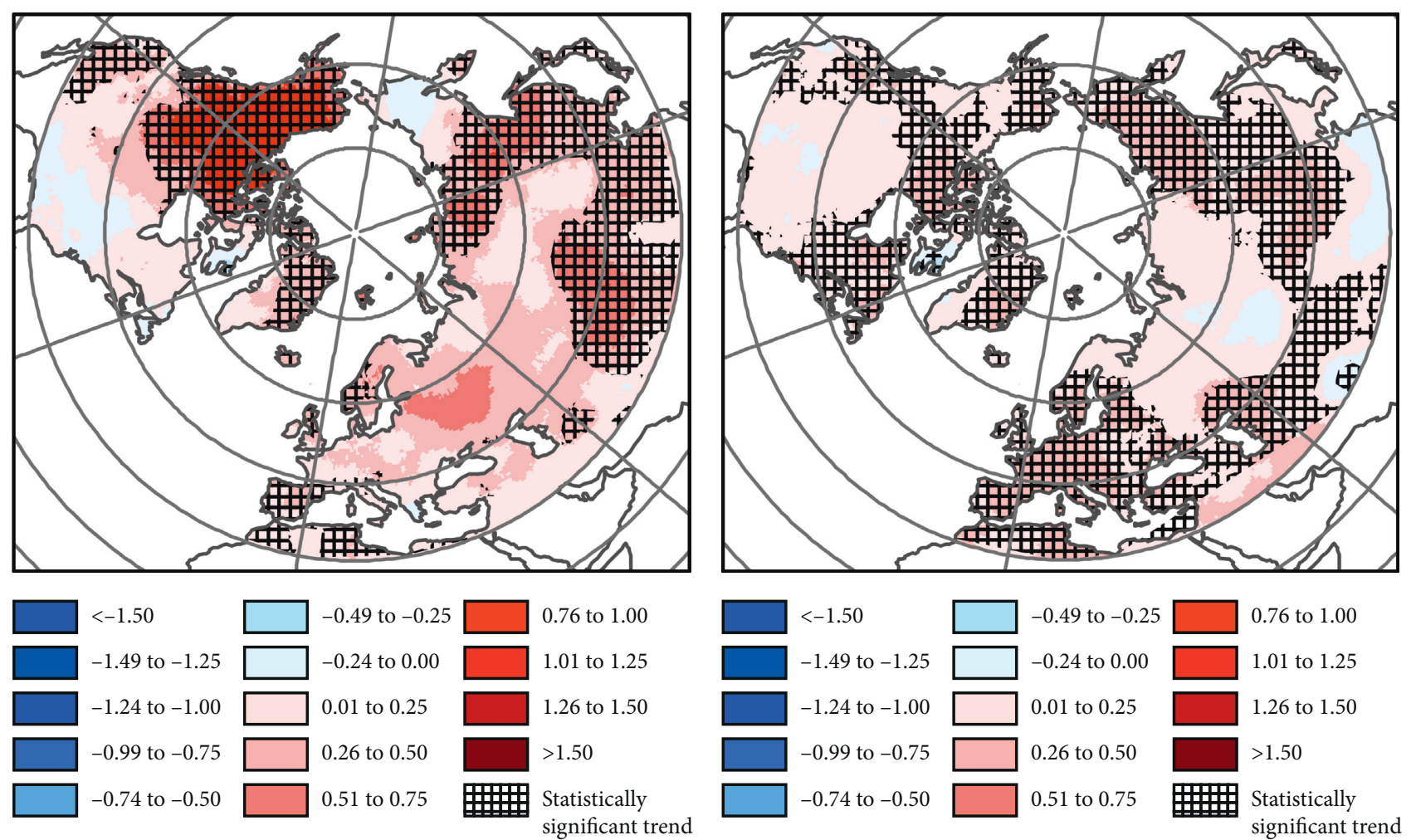

(a)
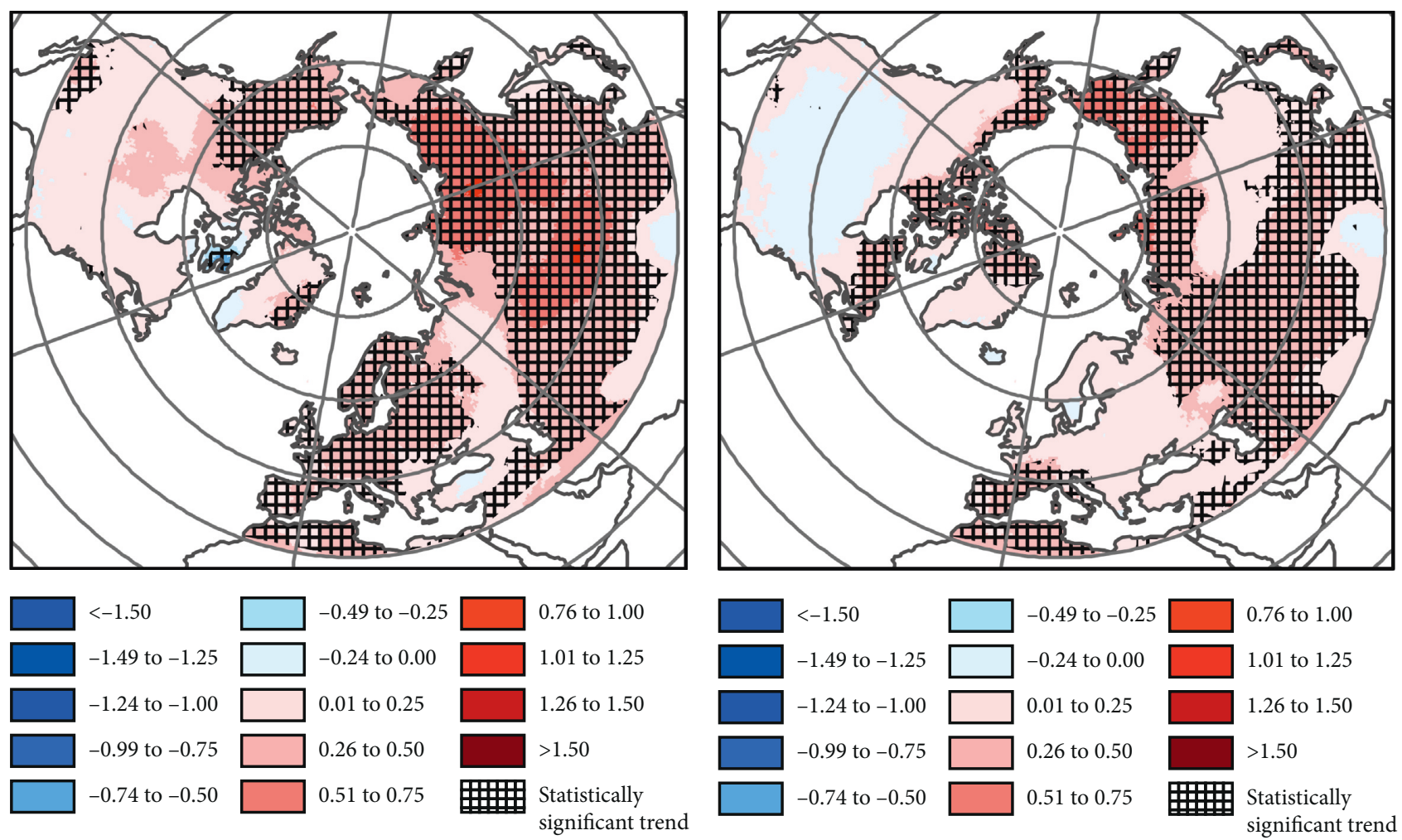

(c)

(d)

Figure 4: Sen's slope trends of annual (a) minimum $\left(T_{\min }\right)$ and (b) maximum $\left(T_{\max }\right)$ monthly temperatures and temperature in (c) April $\left(T_{\text {apr }}\right)$ and $(\mathrm{d})$ October $\left(T_{\text {oct }}\right)$ in the Northern Hemisphere above $30^{\circ} \mathrm{N}$ latitude in $1950-2015$. The magnitude of trends is expressed as a change of temperature in ${ }^{\circ} \mathrm{C}$ over 10 years. 


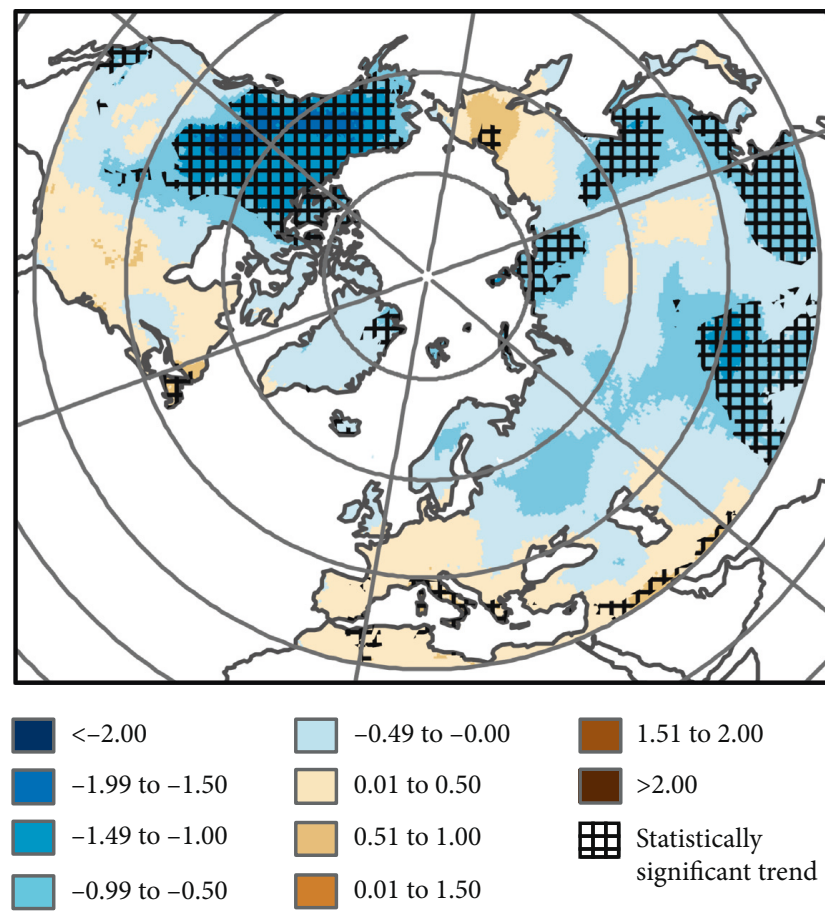

(a)

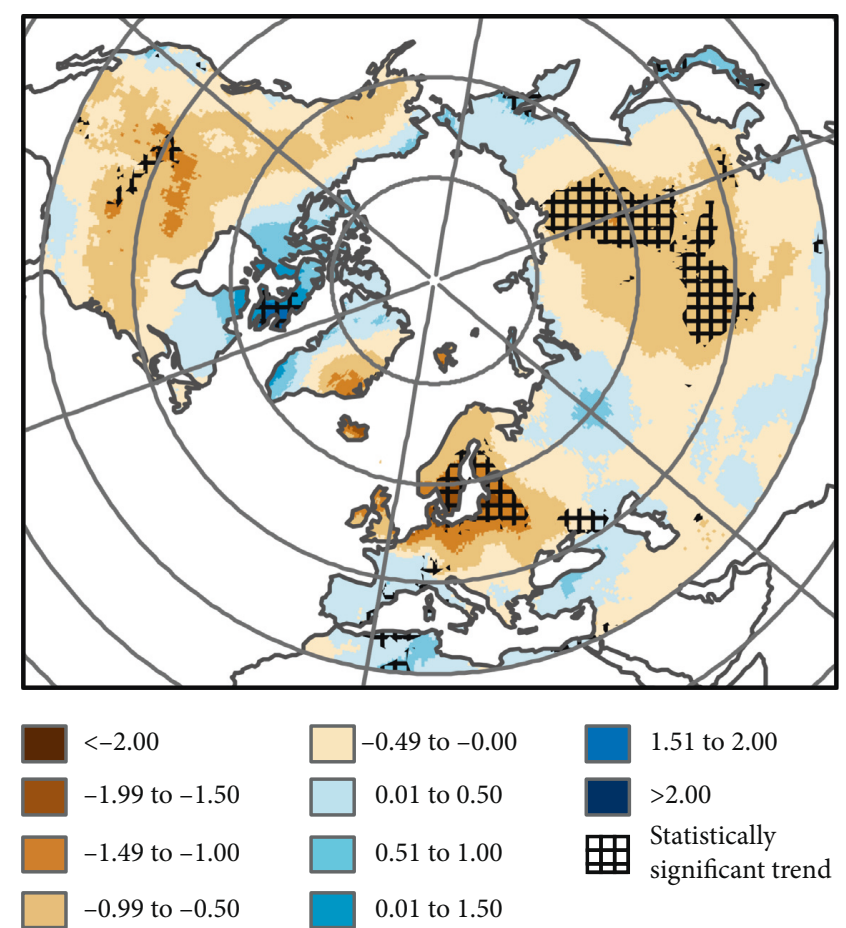

(b)

FIGURE 5: Sen's slope trends of (a) continentality (CCI) and (b) oceanity (KOI) indexes in the Northern Hemisphere above $30^{\circ} \mathrm{N}$ latitude in 1950-2015. The magnitude of trends is expressed as a change of index over 10 years. Blue colours indicate a change towards oceanity and brown towards continentality.

on land surface winter temperatures [35]. PNA and WP patterns have a similar effect on $T_{\min }$ in the northern part of North America. Other NHTPs seem to only have a regional effect on $T_{\min }$ : EA in Europe, SCA in the western part of Eurasia, POL in parts of Siberia, and EP/NP in the Eastern Arctic and Siberia. Positive phases of NAO (AO) and to an extent EA imply larger equator-to-pole temperature gradients during the winter season, which is linked with stronger zonal winds bringing maritime air masses far into the interior parts of continents [36, 37]. In summer, NAO also seems to play a significant role in determining the distribution of surface temperature anomalies across Northern Hemisphere continents, especially over Eurasia and the North Atlantic [38].

The correlations between NHTPs and $T_{\max }$ contribute less to CCI than does $T_{\min }$ (Figure 2). Furthermore, almost all of the selected NHTPs have a merely regional effect on $T_{\max }$. The most important ones are EA for Europe and the Far East, POL for Europe and Southern Siberia, EA/WR for Eastern Europe and the Ural region, and EP/NP primarily for North America and some parts of Eurasia [39]. The most important circulation modes in winter and NAO and PNA in summer appear to have significant correlations only in very discrete and local land surface areas in the Northern Hemisphere (Figure 6).

For KOI, according to correlations between NHTPs and $T_{\text {oct }}$ and $T_{\text {apr }}$, the most important patterns appear to be SCA, EA/WR, POL, and EA for Eurasian regions, PNA for North American regions, NAO for Greenland and Northeastern
Canada, and EP/NP and WP for both Eurasia and North America (Figure 6). The most crucial factor influencing KOI, with reference to its formula, may be patterns that have an opposite effect on temperature in October and April in the same areas during their different phases. This is particularly important within inland regions of Eurasia and North America (low KOI regions) as well as in coastal areas in high and mid latitudes (high KOI regions). Such NHTP patterns are NAO and SCA for Siberia and the Ural region, EA/WR for Eastern Europe, Caucasus, and Turkey, EA for Central Europe and Eastern China, EP/NP for eastern North America, and WP for Northeast Siberia and the Great Plains (Figure 6).

The sum of eight determination coefficients describing the relationship between $T_{\min }, T_{\max }, T_{\text {apr }}$, and $T_{\text {oct }}$ and teleconnection indexes was used as the measure of cumulative effect of selected Northern Hemisphere teleconnection patterns on $T_{\min }, T_{\max }, T_{\text {oct }}$, and $T_{\text {apr }}$ and hence CCI and KOI values (Figure 7). The impact on $T_{\min }$ has a latitudinal extension between $40^{\circ} \mathrm{N}$ and $60^{\circ} \mathrm{N}$ in Eurasia and between $50^{\circ} \mathrm{N}$ and $70^{\circ} \mathrm{N}$ in North America (Figure 7). Such a spatial effect coincides with the extension of the Siberian High to the west in Eurasia and the winter Arctic anticyclone in North America. These areas appear to be sensitive to signs of an NAO phase as well as to a POL, EA, and PNA phase. The cumulative effect on $T_{\max }$ is rather discrete and consequently depends on NHTP patterns representing the Rossby wavetrain: EA, EA/WR, EP/NP, WP, and POL. Given that the CCI is largely contingent on $T_{\min }$, NAO seems to be the 

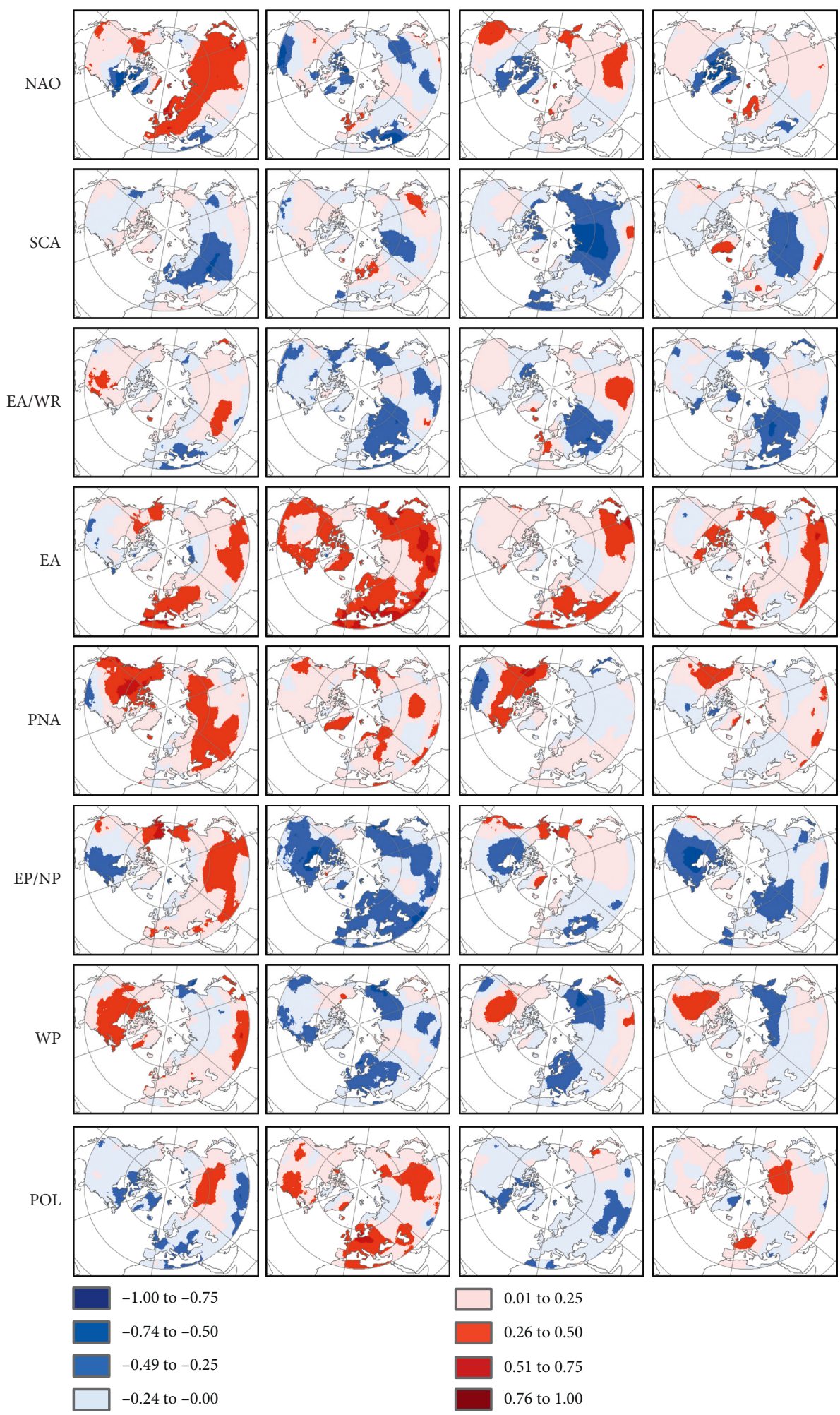

FIgURE 6: Spatial variation of correlation coefficients between indexes of the Northern Hemisphere teleconnection patterns and $T_{\min }, T_{\max }$, $T_{\text {apr }}$, and $T_{\text {oct }}$ in 1950-2015. Correlation coefficients higher than 0.25 and lower than -0.25 are statistically significant $(p<0.05)$.

main contributor to its temporal variation in Eurasia and NAO and PNA in North America. For KOI, the cumulative effect of NHTPs on temperature seems to be strong in Eastern Canada and the northeastern part of Siberia $\left(T_{\text {apr }}\right.$ and $\left.T_{\text {oct }}\right)$ and a little weaker in Western Siberia, the Ural region, and Northern Kazakhstan (only $T_{\text {apr }}$ ). Therefore, the main contributors to the cumulative effect here are EP/NP and WP, while other teleconnection patterns contribute to the cumulative effect only in a particular season, e.g., EA/WR in October and SCA in April (Figure 7). 

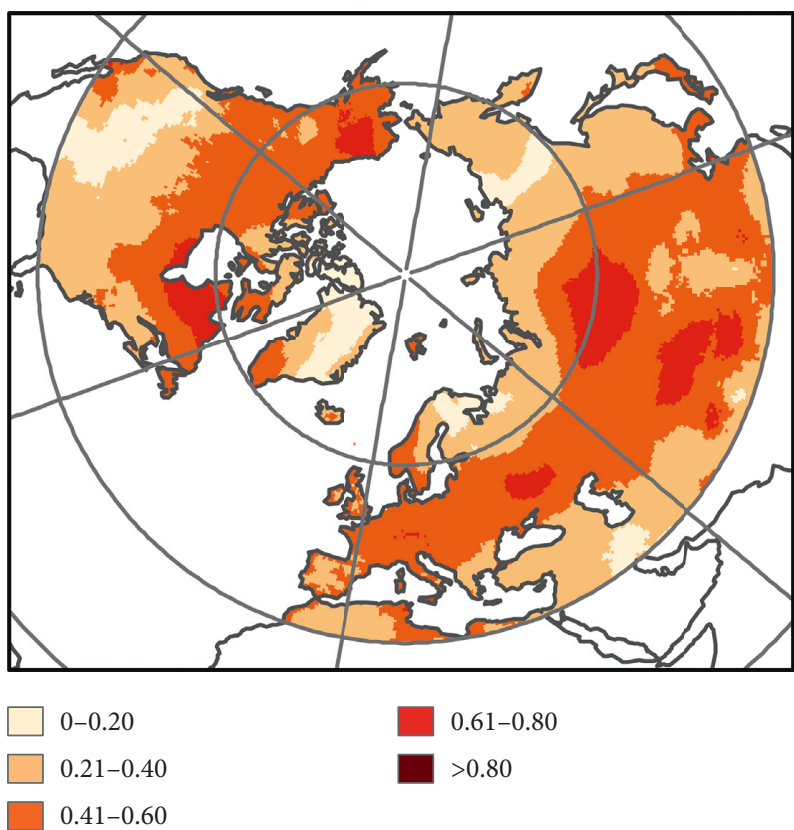

(a)

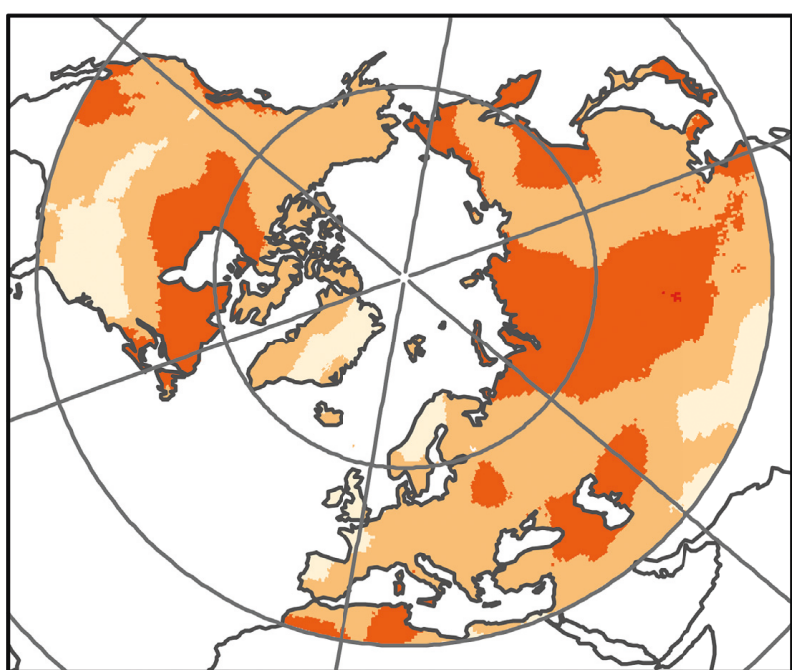

$0-0.20$

$0.21-0.40$

$0.41-0.60$

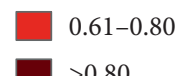

$>0.80$

(c)
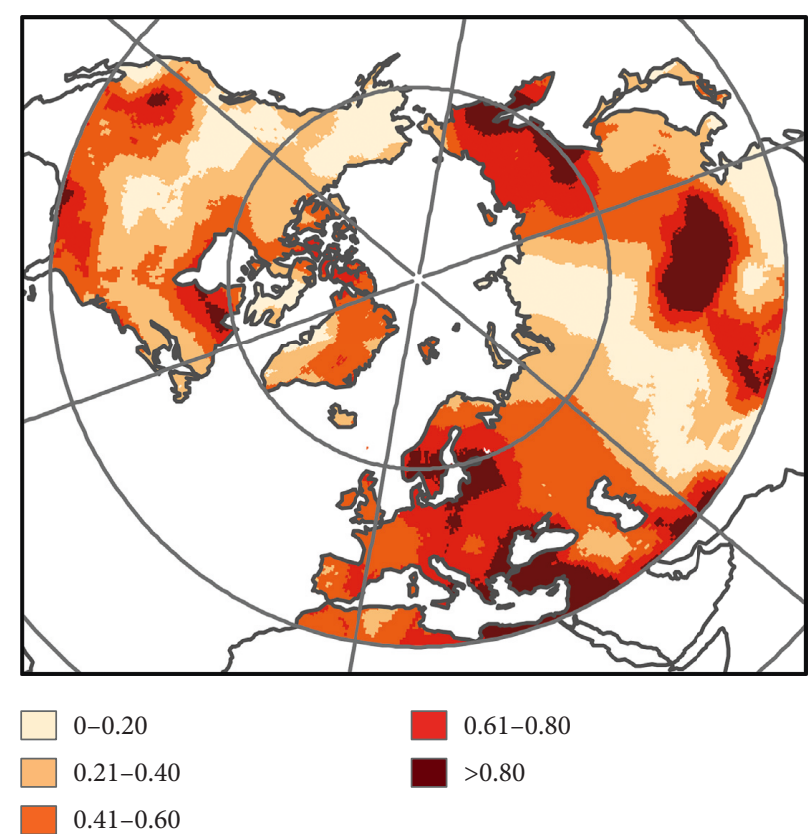

(b)

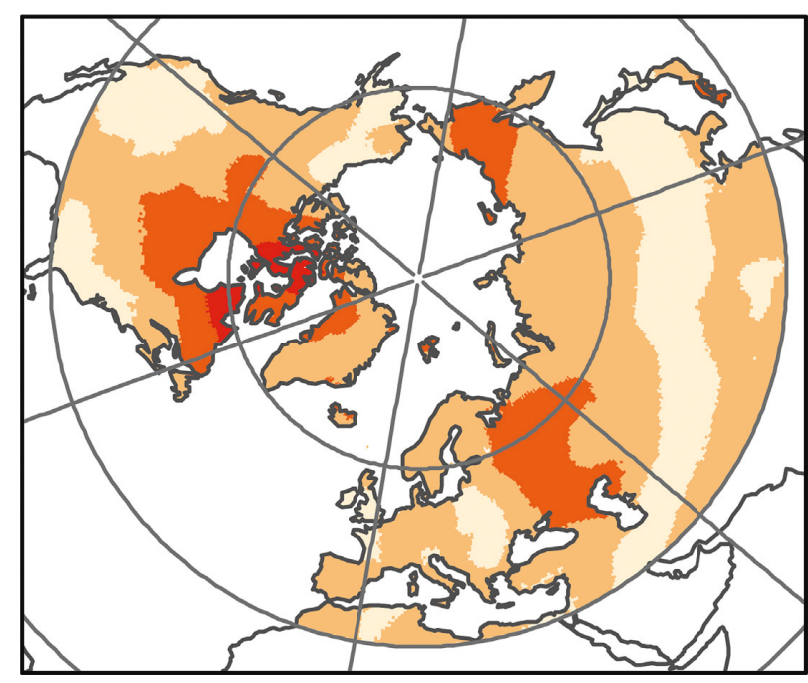

$0-0.20$

$0.21-0.40$

$0.41-0.60$
$0.61-0.80$

$>0.80$

(d)

Figure 7: The spatial distribution of the sum of eight determination coefficients describing the relationship between (a) $T_{\min }$, (b) $T_{\max }$, (c) $T_{\text {apr }}$, and (d) $T_{\text {oct }}$ and selected Northern Hemisphere teleconnection indexes.

Large-scale atmospheric circulation patterns and oscillations affect continentality (CCI) and oceanity (KOI) of many regions in the Northern Hemisphere. Their asymmetry in phases during certain time periods can affect the trends of $\mathrm{CCI}$ and KOI. For instance, the NAO exhibited the predominance of its positive phase in the final three decades of the twentieth century, with a peak in the early-1990s [40-42]. This coincided with the change in magnitude and shift in position of the centres of action, especially in the cold season of the year: the Azores High, Siberian High, North
American High, Icelandic Low, and Aleutian Low. This is also confirmed by trends of CCI and KOI (Figure 5).

\section{Conclusions}

This paper has investigated variations in continentality and oceanity in the middle and high Northern Hemisphere latitudes in the period 1950-2015. The Conrad Continentality Index (CCI) and Kerner Oceanity Index (KOI) were employed for this purpose. The impacts of atmospheric 
circulation on the variability of these indexes were also analysed.

The spatial pattern of climate continentality and oceanity is contingent on distance to the ocean, topography, and atmospheric circulation. The interannual variation of surface air temperatures of the coldest month $\left(T_{\min }\right)$ is greater than temperature variations during summer months in the majority of the study area. Therefore, the most important factor determining the magnitude of annual air temperature amplitude and CCI values is $T_{\min }$. The warmest month's temperature $\left(T_{\max }\right)$ is the leading factor for CCI only in the western part of Europe and North Africa. The temporal variation of differences between April $\left(T_{\text {apr }}\right)$ and October $\left(T_{\text {oct }}\right)$ surface air temperatures is larger than the variation of annual air temperature amplitude, and it has a greater impact on the temporal dynamics of KOI. The KOI in central parts of continents better correlates with air temperatures in April, while in coastal areas KOI is closely connected to October temperature fluctuations.

Since 1950 in many regions of the Northern Hemisphere, positive and statistically significant trends of $T_{\min }, T_{\max }$, $T_{\text {apr }}$, and $T_{\text {oct }}$ were recorded. The direction and magnitude of the CCI trend were determined by the ratio of $T_{\min }$ and $T_{\max }$ trends. Climate continentality has declined in areas where the difference between $T_{\min }$ and $T_{\max }$ trend values is positive, and vice versa. For example, the dramatic reduction in strength of the Siberian High, which is responsible for extreme continental conditions over larger parts of Siberia and East Asia, has been observed since the 1980s [43, 44], and it was primarily influenced by dominant positive phases of NAO/AO and EA patterns. Meanwhile, the $T_{\text {apr }}$ and $T_{\text {oct }}$ positive trend spatial patterns resulted in significant changes in KOI over most of Eurasia and the northern part of North America in the period researched. According to KOI, climate continentality has increased in the Baltic Sea region and in parts of East Siberia, Mongolia, and the Great Plains, while the statistically significant increase in oceanity was mostly found over the northern part of Canada. According to CCI, continentality has decreased in western parts of Canada and the USA as well as in parts of Central and Eastern Asia. In summary, we can highlight that statistically significant CCI trends on larger areas display reduced continentality, while statistically significant KOI trends show decreased oceanity from 1950 until 2015. This can be explained by the fact that, during the study period, larger temperature increases were noted in winter and spring. A statistically significant decrease of CCI in areas surrounding the North Atlantic and Eastern Arctic and within the Southeastern USA and an increase of CCI in Inner Mongolia and the Mediterranean seem to be the consequence of the change in position and magnitude of centres of action, both semipermanent (e.g., NAO) and seasonal (e.g., the Siberian High) $[45,46]$.

El Kenawy et al. [14] have asserted that changes in the spatial variability of continentality are closely coupled with the Atlantic modes of variability, especially with the Eastern Atlantic pattern (in the Mediterranean, Middle East, and northern part of Africa). Similar findings concerning the North Atlantic Oscillation were also detected at an earlier point in the large domain extending from Eastern Canada to the Central Arctic via Europe [47-49]. On the contrary, the high spatial variability of continentality as well as changes in its gradients in specific areas (e.g., Greenland) could be due not only to large-scale circulation patterns but also to local effects [50].

Not all areas of decreasing (increasing) CCI (KOI) can however be explained by the prevalence of particular teleconnection patterns. The higher latitudes of North America and the most northeastern parts of Siberia were most likely affected by the retreat of seasonal sea ice (later freezing time) driven by an increase in sea surface temperatures [51].

It is very likely that continentality will alter in the future and its changes may be amplified in the following decades. Therefore, climate projections are important to assess potential continentality/oceanity changes and to evaluate the associated impact on natural and anthropogenic systems.

\section{Data Availability}

The gridded mean monthly air temperature values were derived from the CRU TS4.00 database (https://crudata.uea. ac.uk/cru/data/hrg/). The Northern Hemisphere teleconnection patterns (NHTPs) were derived from the website of NOAA Center for Weather and Climate Prediction (http: //www.cpc.ncep.noaa.gov/data/teledoc/telecontents.shtml).

\section{Conflicts of Interest}

The authors declare that there are no conflicts of interest regarding the publication of this paper.

\section{Acknowledgments}

This work was supported by the Institute of Geosciences of Vilnius University.

\section{References}

[1] J. J. M. Hirschi, B. Sinha, and S. A. Josey, "Global warming and changes of continentality since 1948," Weather, vol. 62, no. 8, pp. 215-221, 2007.

[2] B. D. Santer, P.-C. Stephen, M. D. Zelinka et al., "Human influence on the seasonal cycle of tropospheric temperature," Science, vol. 361, no. 6399, article eaas8806, 2018.

[3] J. L. Cohen, J. C. Furtado, M. Barlow, V. A. Alexeev, and J. E. Cherry, "Asymmetric seasonal temperature trends," Geophysical Research Letters, vol. 39, no. 4, 2012.

[4] F. Ji, Z. Wu, J. Huang, and E. P. Chassignet, "Evolution of land surface air temperature trend," Nature Climate Change, vol. 4, pp. 462-466, 2014.

[5] W. Gorczyński, "O wyznaczeniu stopnia kontynentalizmu według amplitud temperatury," Sprawozdanie z posiedzeń Towarzystwa Naukowego Warszwskiego, Warsaw Scientific Society, Warsaw, Poland, 1918.

[6] D. Brunt, "Climatic continentality and oceanity," The Geographical Journal, vol. 64, no. 1, pp. 44-43, 1924.

[7] N. Raunio, "The effect of local factors on the meteorological observations at Torshavn," Geophysica, vol. 3, pp. 173-179, 1948. 
[8] E. Baltas, "Spatial distribution of climatic indices in northern Greece," Meteorological Applications, vol. 14, no. 1, pp. 69-78, 2007.

[9] A. Deniz, H. Toros, and S. Incecik, "Spatial variations of climate indices in Turkey," International Journal of Climatology, vol. 31, no. 3, pp. 394-403, 2011.

[10] S. M. Gadiwala, F. Burke, T. M. Alam, S. Nawaz-ul-Huda, and M. Azam, "Oceanity and continentality climate indices in Pakistan," Malaysian Journal of Society and Space, vol. 9, no. 4, pp. 57-66, 2013.

[11] C. Andrade and J. Corte-Real, "Assessment of the spatial distribution of continental-oceanic climate indices in the Iberian Peninsula," International Journal of Climatology, vol. 37, no. 1, pp. 36-45, 2017.

[12] J. Vilček, J. Škvarenina, J. Vido, P. Nalevanková, R. Kandrík, and J. Škvareninová, "Minimal change of thermal continentality in Slovakia within the period 1961-2013," Earth System Dynamics, vol. 7, no. 3, pp. 735-744, 2016.

[13] R. Brázdil, K. Chromá, P. Dobrovolný, and R. Tolasz, “Climate fluctuations in the Czech Republic during the period 19612005," International Journal of Climatology, vol. 29, no. 2, pp. 223-242, 2009.

[14] A. M. El Kenawy, M. F. McCabe, S. M. Vicente-Serrano, S. M. Robaa, and J. I. Lopez-Moreno, "Recent changes in continentality and aridity conditions over the Middle East and North Africa region, and their association with circulation patterns," Climate Research, vol. 69, no. 1, pp. 25-43, 2016.

[15] B. V. Poltaraus and D. B. Staviskiy, "The changing continentality of climate in Central Russia," Soviet Geography, vol. 27, no. 1, pp. 51-58, 1986.

[16] S. A. Harris, "Continentality index: its uses and limitations applied to permafrost in the Canadian Cordillera," Physical Geography, vol. 10, no. 3, pp. 270-284, 1989.

[17] D. I. Nazimova, V. G. Tsaregorodtsev, and N. M. Andreyeva, "Forest vegetation zones of Southern Siberia and current climate change," Geography and Natural Resources, vol. 31, no. 2, pp. 124-131, 2010.

[18] L. Gorczynski, "The calculation of the degree of continentality," Monthly Weather Review, vol. 50, no. 7, pp. 369-370, 1922.

[19] O. V. Johansson, "Uber die Asymmetrie der meteorologischen Schwankungen," Societas Scientiarum Fennica Commentationes Physico-Mathematicae, vol. 3, 1926.

[20] V. Conrad, "Usual formulas of continentality and their limits of validity," Transactions of the American Geophysical Union, vol. 27, no. 5, pp. 663-664, 1946.

[21] A. Marsz and S. Rakusa-Suszczewskis, "Charakterystyka ekologiczna rejonu Zatoki Admiralicji (King George Island, South Shetland Islands). 1. Klimat i obszary wolne od lodu," Kosmos, vol. 36, pp. 103-127, 1987.

[22] F. Kerner, "Thermoisodromen, Versuch einer kartographischen Darstellung des jahrlichen Ganges der Lufttemperatur (Wien)," K. K. Geographische Gesellschaft, vol. 6, no. 3, p. 30, 1905.

[23] I. C. Harris and P. D. Jones, "CRU TS4.00: Climatic Research Unit (CRU) Time-Series (TS) version 4.00 of high-resolution gridded data of month-by-month variation in climate (Jan. 1901-Dec. 2015)," Centre for Environmental Data Analysis, 2017.

[24] I. C. Harris, P. D. Jones, T. J. Osborn, and D. H. Lister, "Updated high-resolution grids of monthly climatic observations-the CRU TS3.10 Dataset," International Journal of Climatology, vol. 34, no. 3, pp. 623-642, 2014.
[25] M. New, M. Hulme, and P. Jones, "Representing twentiethcentury space-time climate variability. Part I: development of a 1961-90 mean monthly terrestrial climatology," Journal of Climate, vol. 12, no. 3, pp. 829-856, 1999.

[26] M. Tanarhte, P. Hadjinicolaou, and J. Lelieveld, "Intercomparison of temperature and precipitation data sets based on observations in the Mediterranean and the Middle East," Journal of Geophysical Research: Atmospheres, vol. 117, no. D12, 2012.

[27] R. G. Lauritsen and J. C. Rogers, "US diurnal temperature range variability and regional causal mechanisms, 19012002," Journal of Climate, vol. 25, no. 20, pp. 7216-7231, 2012.

[28] M. Belda, E. Holtanova, T. Halenka, and J. Kalvova, "Climate classification revisited: from Koppen to Trewartha," Climate Research, vol. 59, no. 1, pp. 1-13, 2014.

[29] M. A. A. Zarch, B. Sivakumar, and A. Sharma, "Droughts in a warming climate: a global assessment of standardized precipitation index (SPI) and Reconnaissance drought index (RDI)," Journal of Hydrology, vol. 526, pp. 183-195, 2015.

[30] K. Takaya and H. Nakamura, "Mechanisms of intraseasonal amplification of the cold Siberian high," Journal of the Atmospheric Sciences, vol. 62, no. 12, pp. 4423-4440, 2005.

[31] J. E. Jones and J. Cohen, "A diagnostic comparison of Alaskan and Siberia strong anticyclones," Journal of Climate, vol. 24, no. 10, pp. 2599-2611, 2011.

[32] M. D. S. Mesquita, D. E. Atkinson, and K. I. Hodges, "Characteristics and variability of storm tracks in the north Pacific, Bering Sea, and Alaska," Journal of Climate, vol. 23, no. 2, pp. 294-311, 2010.

[33] J. C. Stroeve, M. C. Serreze, A. Barrett, and D. N. Kindig, "Attribution of recent changes in autumn cyclone associated precipitation in the Arctic,” Tellus, vol. 63, no. 4, pp. 653-663, 2011.

[34] Y. K. Lim, “The East Atlantic/West Russia (EA/WR) teleconnection in the North Atlantic: climate impact and relation to Rossby wave propagation," Climate Dynamics, vol. 44, no. 11-12, pp. 3211-3222, 2015.

[35] J. Cohen, K. Saito, and D. Entekhabi, "The role of the Siberian high in Northern Hemisphere climate variability," Geophysical Research Letters, vol. 28, no. 2, pp. 299-302, 2001.

[36] D. W. J. Thompson and J. M. Wallace, "The Arctic Oscillation signature in the wintertime geopotential height and temperature fields," Geophysical Research Letters, vol. 25, no. 9, pp. 1297-1300, 1998.

[37] S. He, Y. Gao, F. Li, H. Wang, and Y. He, "Impact of Arctic Oscillation on the East Asian climate: a review," Earth-Science Reviews, vol. 64, pp. 48-62, 2017.

[38] C. K. Folland, J. Knight, H. W. Linderholm, D. Fereday, S. Ineson, and J. W. Hurrell, "The summer North Atlantic Oscillation: past, present, and future," Journal of Climate, vol. 22, no. 5, pp. 1082-1103, 2009.

[39] B. K. Tan, J. C. Yuan, Y. Dai, and S. B. Feldstein, "The linkage between the eastern Pacific teleconnection pattern and convective heating over the tropical western Pacific," Journal of Climate, vol. 28, no. 14, pp. 5783-5794, 2015.

[40] J. W. Hurrell and C. Deser, "North Atlantic climate variability: the role of the North Atlantic Oscillation," Journal of Marine Systems, vol. 78, no. 1, pp. 28-41, 2009.

[41] T. L. Delworth, F. Zeng, G. A. Vecchi, X. Yang, L. Zhang, and R. Zhang, "The North Atlantic Oscillation as a driver of rapid climate change in the Northern Hemisphere," Nature Geoscience, vol. 9, no. 7, pp. 509-512, 2016.

[42] A. Hannachi, D. M. Straus, C. L. Franzke, S. Corti, and T. Woollings, "Low-frequency nonlinearity and regime 
behavior in the Northern Hemisphere extratropical atmosphere," Reviews of Geophysics, vol. 55, no. 1, pp. 199-234, 2017.

[43] F. Panagiotopoulos, M. Shahgedanova, A. Hannachi, and D. B. Stephenson, "Observed trends and teleconnections of the Siberian high: a recently declining center of action," Journal of Climate, vol. 18, no. 9, pp. 1411-1422, 2005.

[44] J. Yun, K.-J. Ha, and Y.-H. Jo, "Interdecadal changes in winter surface air temperature over East Asia and their possible causes," Climate Dynamics, vol. 51, no. 4, pp. 1375-1390, 2017.

[45] N. C. Johnson, "The continuum of Northern Hemisphere teleconnection patterns and a description of the NAO shift with the use of self-organizing maps," Journal of Climate, vol. 21, no. 23, pp. 6354-6371, 2008.

[46] G. W. K. Moore, I. A. Renfrew, and R. S. Pickart, "Multidecadal mobility of the North Atlantic Oscillation," Journal of Climate, vol. 26, no. 8, pp. 2453-2466, 2013.

[47] D. Chen and C. Hellstrom, "The influence of the North Atlantic Oscillation on the regional temperature variability in Sweden: spatial and temporal variations," Tellus A: Dynamic Meteorology and Oceanography, vol. 51, no. 4, pp. 505-516, 1999.

[48] R. M. M. Crawford, C. E. Jeffree, and W. G. Rees, "Paludification and forest retreat in northern oceanic environments," Annals of Botany, vol. 91, no. 2, pp. 213-226, 2003.

[49] A. Vladuț, N. Nikolova, and M. Licurici, "Evaluation of thermal continentality within southern Romania and northern Bulgaria (1961-2015)," Geofizika, vol. 35, no. 1, pp. 1-18, 2018.

[50] J. Abermann, B. Hansen, M. Lund, S. Wacker, M. Karami, and J. Cappelen, "Hotspots and key periods of Greenland climate change during the past six decades," Ambio, vol. 46, no. 1, pp. 3-11, 2017.

[51] C. M. Serreze, A. Crawford, J. Stroeve, A. Barrett, and R. A. Woodgate, "Variability, trends, and predictability of seasonal sea ice retreat and advance in the Chukchi Sea," Journal of Geophysical Research: Oceans, vol. 121, no. 10, pp. 7308-7325, 2016. 

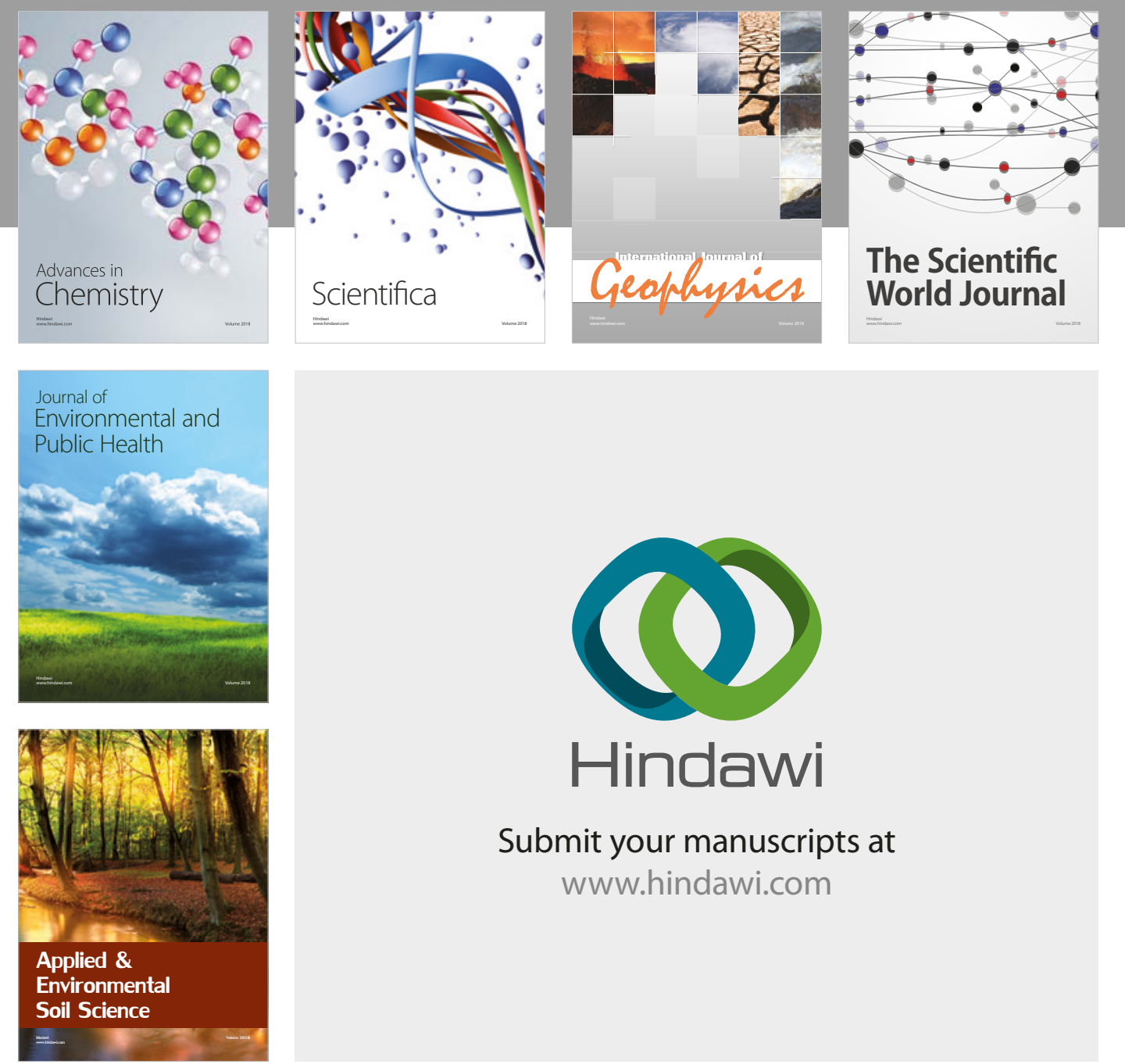

The Scientific

\section{World Journal}
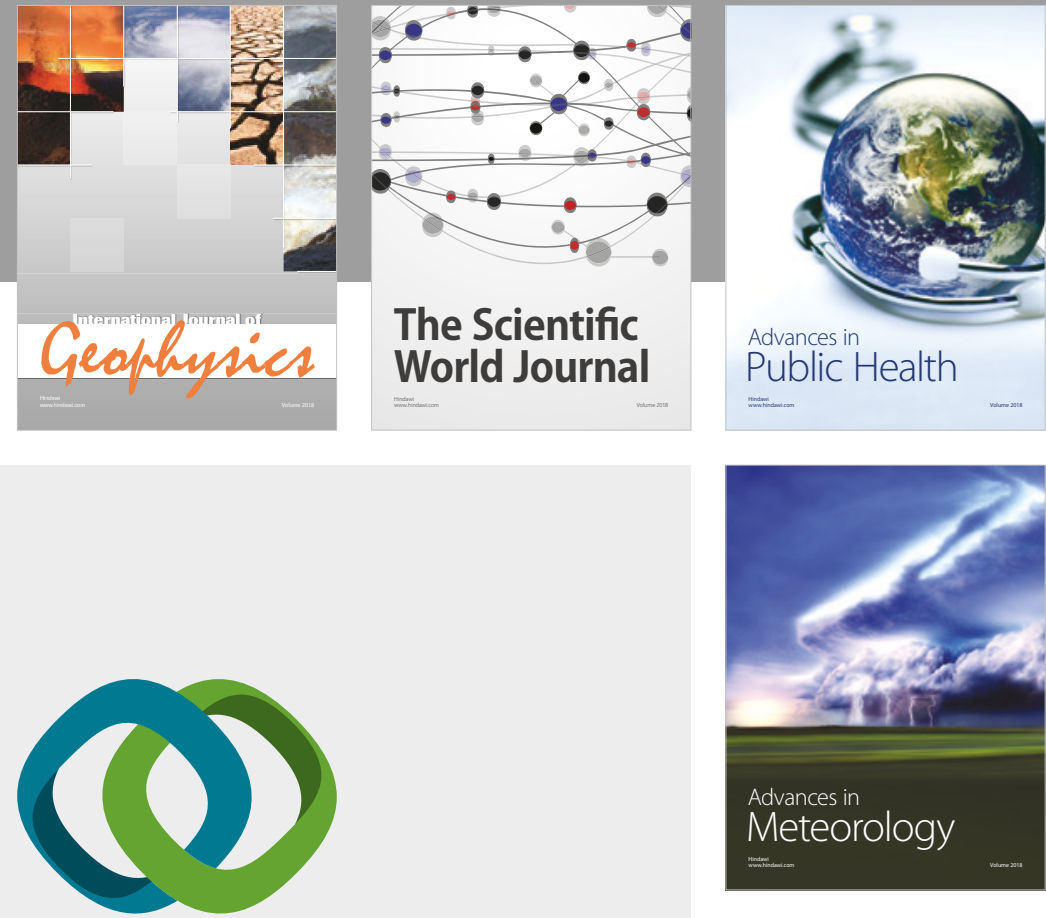

Advan

Public Health

\section{Hindawi}

Submit your manuscripts at

www.hindawi.com
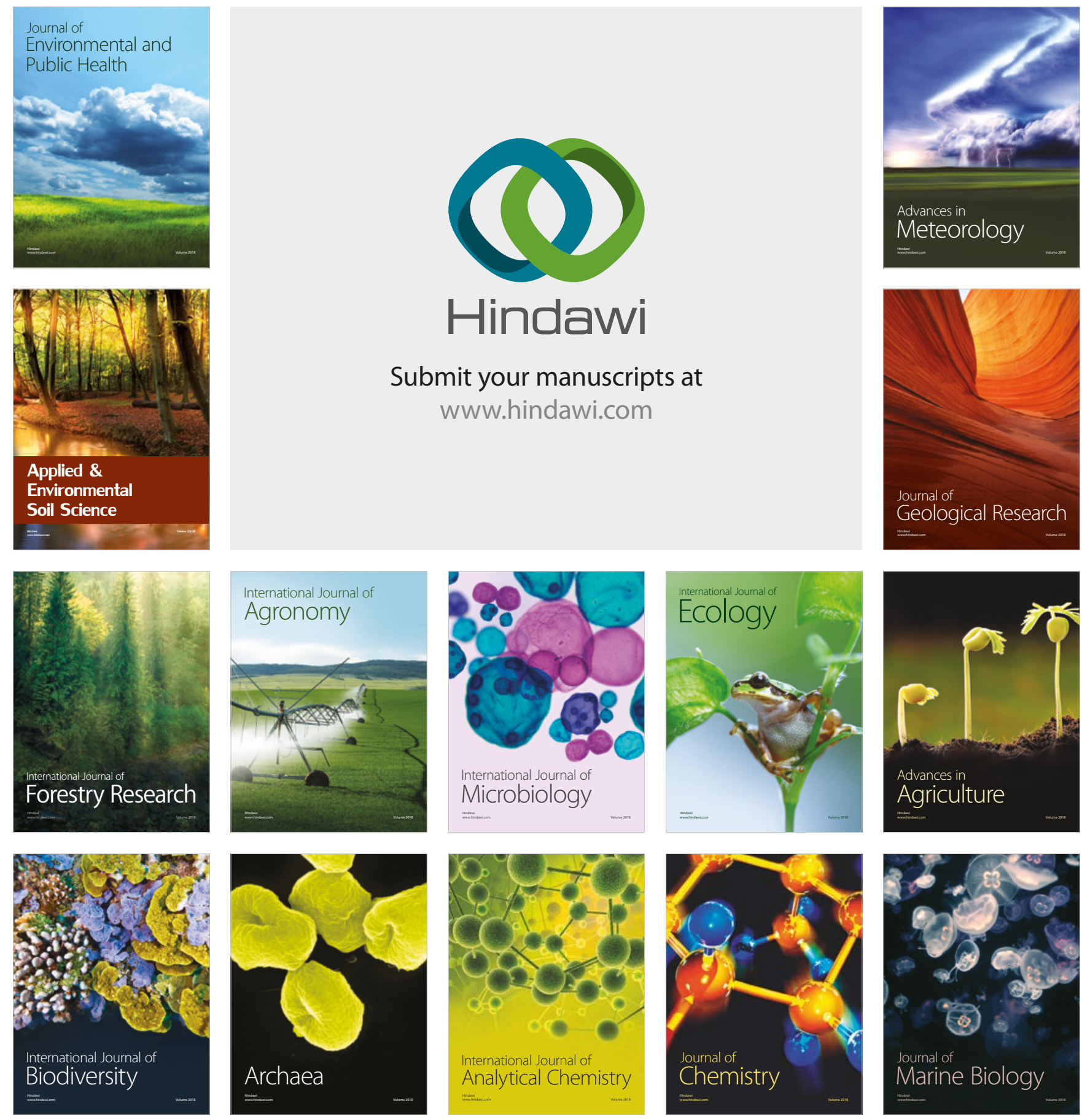